Washington State Department of Health, Injury Prevention Program, Olympia, Washington M LeMier

Harborview Injury Prevention and Research Center and the Department of Epidemiology, University of Washington, Seattle, Washington P Cummings

University of Texas, Southwestern Medical School, Dallas, Texas T A West

Correspondence to: Mary LeMier, Office of Community Wellness and Prevention, Injury Prevention Program, Mail Stop 7832, Olympia, WA 98504, USA

mary.lemier@doh.wa.gov

\title{
Accuracy of external cause of injury codes reported in Washington State hospital discharge records
}

\author{
M LeMier, P Cummings, T A West
}

\begin{abstract}
Objective-To evaluate the accuracy of external cause of injury codes ( $E$ codes) reported in computerized hospital discharge records.

Methods-All civilian hospitals in Washington State submit computerized data for each hospital discharge to a file maintained by the Department of Health. In 1996, 32 hospitals accounted for $80 \%$ of the injury related discharges in this file; from these hospitals, we sampled 1260 computerized records for injured patients in a stratified, but random, manner. An expert coder then visited the 32 study hospitals, reviewed the medical records that corresponded to each computerized record, and assigned an $E$ code for that hospitalization. The computerized $E$ code information was compared with codes provided by the expert reviewer.

Results - The incidence of hospitalization for injury based upon computerized hospital discharge data was very similar to that based upon chart review: incidence rate ratio 1.0 (95\% confidence interval 1.00 to 1.02). Computerized hospital discharge data correctly ranked injuries in regard to both mechanism and intent. Overall agreement on coding was $87 \%$ for mechanism of injury, $95 \%$ for intent of injury, and $66 \%$ for the complete $E$ code. The sensitivity of computerized hospital discharge data for identification of falls, motor vehicle traffic injuries, poisonings, and firearm injuries was $91 \%$ or better. The predictive value positive of coding for these four categories of injury ranged from $\mathbf{8 8 \%}$ for motor vehicle traffic injuries to $94 \%$ for poisonings. The amount of agreement for intent coding ranged from $84 \%$ for firearm injuries to $99 \%$ for falls. Agreement on coding of the complete $E$ code ranged from $\mathbf{5 7 \%}$ for firearm injuries to $72 \%$ for poisonings.
\end{abstract}

Conclusions-Computerized hospital discharge data can be used with confidence to determine how many injuries are treated in a hospital setting and the relative magnitude of various categories of injury. E codes reported in hospital discharge data are a reliable source of information on the mechanism and intent of injury, the two types of information most often used for injury related analyses and priority setting. The detail codes (complete $\mathrm{E}$ codes) reported in hospital discharge codes are less reliable and must be used with caution.

(Injury Prevention 2001;7:334-338)

Keywords: E codes; hospital discharge records; injury surveillance

Hospital discharge information are often used for surveillance and research regarding injuries. ${ }^{12}$ Injuries treated in a hospital setting are coded using the International Classification of Diseases, 9th Revision, Clinical Modification (ICD-9-CM), published by the United States Department of Health and Human Services. ${ }^{3}$ The ICD-9-CM includes codes for the anatomical nature of injury (such as a broken leg, concussion, contusion) as well as the external causes of injury (such motor vehicle, firearm, poison). If used correctly, external cause of injury codes, commonly referred to as E codes, can identify injuries according to intent (unintentional, suicide, assault), mechanism (motor vehicle, firearm, poison, etc) and detailed circumstances (such as drivers versus passengers in motor vehicle crashes or handguns versus rifles in firearm incidents).

In 1998, 23 states required the reporting of $\mathrm{E}$ codes on hospital discharge records. ${ }^{4}$ Comparisons between states with and without $\mathrm{E}$ code reporting mandates show that states with mandates are more likely, on average, to have a higher percentage of $\mathrm{E}$ coded injury discharges. ${ }^{45}$ In Washington State, where a mandate for $\mathrm{E}$ coding has existed since 1989, the completeness of $\mathrm{E}$ coding on discharge records with a principal diagnosis of injury was $99 \%$ in 1998.

If $\mathrm{E}$ codes reported in hospital discharge records are to be used for surveillance of injuries, it would be useful to know how accurate these codes are. The present study was undertaken to determine the extent to which $\mathrm{E}$ codes on computerized hospital discharge records accurately identify the mechanism, intent, and detailed characteristics of injuries and the relative magnitude of specific types of injury. We also hoped to identify actions that might be taken to improve the quality of the data. 


\section{Methods}

For this study, $1260 \mathrm{E}$ coded hospital discharge records were sampled from the 1996 computerized hospital discharge data file maintained by the Washington State Department of Health. This computerized file included information on all inpatient discharges from acute care civilian hospitals in Washington. Computerized discharge records included in the study were those with an external cause of injury code (E800-E869, E880-E929, E950-E999), excluding codes for medical misadventures, complications or abnormal reactions related to medical care, or adverse effects of medication in therapeutic use (E870-E879, E930-E949). Sampling was made without regard to discharge status; thus fatal and non-fatal hospitalizations were sampled.

We restricted the sampling frame to 32 Washington hospitals that accounted for $80 \%$ of injury related hospitalizations in 1996. We selected discharge records from the computerized discharge data using probability proportional to size sampling. ${ }^{6}$

Injuries attributed to firearms and poisons were over sampled to ensure that the final sample contained enough intentional injuries to allow for meaningful analysis of intent coding. The vast majority of injuries are unintentional; firearm and poisoning injuries are the most likely to be intentional.

To assess the accuracy of hospital discharge data, a "gold standard" or "expert record" was developed by a medical record administrator trained in injury coding. Data for the expert record were obtained by the expert reviewer through on-site reviews of medical records at the 32 study hospitals. Information regarding the injury was abstracted from each medical record, including the face sheet, pre-hospital transport narrative, emergency department record, admission history and physical, nursing assessment, physicians' progress notes, and discharge summary. The record expert was blinded to the $\mathrm{E}$ codes reported in the hospital discharge records.

Table 1 Injury estimates based computerized hospital discharge data compared to expert review of medical records from 32 study hospitals *

\begin{tabular}{llll}
\hline & $\begin{array}{l}\text { Estimated counts based } \\
\text { upon computerized } \\
\text { hospital discharge data }\end{array}$ & $\begin{array}{l}\text { Estimated counts based } \\
\text { upon expert review of } \\
\text { medical records }\end{array}$ & $\begin{array}{l}\text { Incidence ratio } \\
\text { (95\% CI) }\end{array}$ \\
\hline Total all categories & 29693 & 29378 & $1.01(1.00$ to 1.02$)$ \\
Falls & 12835 & 12593 & $1.02(0.99$ to 1.05$)$ \\
Motor vehicle traffic & 4129 & 3745 & $1.10(1.03$ to 1.18$)$ \\
Poison & 2949 & 2808 & $1.05(1.01$ to 1.09$)$ \\
Struck & 1152 & 1231 & $0.94(0.75$ to 1.12$)$ \\
Cut & 992 & 928 & $1.07(0.90$ to 1.24$)$ \\
Overexertion & 736 & 704 & $1.05(0.72$ to 1.37$)$ \\
Transport & 576 & 736 & $0.78(0.52$ to 1.03$)$ \\
Machinery & 384 & 480 & $0.80(0.60$ to 1.00$)$ \\
Firearm & 370 & 379 & $0.98(0.82$ to 1.14$)$ \\
Other and unspecified & 1984 & 1639 & $1.21(0.94$ to 1.48$)$ \\
Late effects of injury & 2305 & 2767 & $0.83(0.72$ to 0.94$)$ \\
Intent of injury & 25735 & 25258 & $1.02(1.00$ to 1.03$)$ \\
$\quad$ Unintentional & 2532 & 2386 & $1.06(0.99$ to 1.13$)$ \\
$\quad$ Suicide & 1202 & 1307 & $0.92(0.80$ to 1.04$)$ \\
$\quad$ Assault & 223 & 426 & $0.52(0.15$ to 0.90$)$ \\
$\quad$ Other and undetermined & &
\end{tabular}

${ }^{\star}$ Representing $80 \%$ of Washington's injury related hospitalizations for calendar year 1996 . †Mechanism and intent categories based upon McLoughlin et al. ${ }^{9}$
Injuries were assigned an $\mathrm{E}$ code based on ICD-9-CM guidelines, supplemental instructions issued by the Washington State Department of Health, and special rules in effect for 1996 as outlined in the official guidelines for coding and reporting published by the Department of Health and Human Services. ${ }^{78}$

The expert records were keyed and linked with computerized hospital discharge records using a deterministic method that successfully matched all records. Twenty three hospital discharge records could not be located at the study hospitals and were eliminated from the sample. The probability weights of the sample were adjusted to reflect the elimination of these records.

The data available for analysis from the expert review and hospital discharge records included patient age, sex, discharge date, $\mathrm{E}$ code, and a response to the question "Is this the first hospitalization for this injury". In addition, group codes for mechanism of injury and intent of injury were created for each hospital discharge and expert record using the complete E code and grouping guidelines recommended by the Centers for Disease Control (CDC). ${ }^{9}$

The list of $\mathrm{E}$ codes used to define the various categories of injury were identical to those presented in the CDC's recommended framework for injury classification. ${ }^{9}$ However, we made a separate category for $\mathrm{E}$ codes indicating late effects of injury: E929(.0.5), E929.8, E959, E969, or E989. For some categories of injury, the sample of records was too small to allow for meaningful analysis. Categories of injury were excluded from the results and discussion sections if the sample size was less than 15 .

\section{STATISTICAL ANALYSIS}

We calculated (a) estimated counts of injuries by mechanism of injury; (b) incidence ratios by mechanism of injury; (c) estimates of sensitivity and predictive value positive and (d) inter-rater agreement (observed agreement and the kappa measure of agreement adjusted for chance). ${ }^{10}$ When appropriate, all calculations accounted for sampling weights, finite population corrections, and strata using linearization methods. ${ }^{6}$ STATA statistical software was used for the data analysis. ${ }^{11}$

\section{Results}

We found that computerized hospital discharge data correctly ranked injuries in regard to both mechanism and intent (table 1). The 10 leading causes of injury hospitalization in rank order were falls, motor vehicle crashes, poisonings, late effects of injuries, injuries from being struck by or against an object, cuts, overexertion, transport injuries (other than motor vehicle traffic), machinery related injuries, and firearm injuries. The majority of these injuries were unintentional; a relatively small percentage was attributed to suicide attempts and assaults.

We compared the incidence of injuries from computerized hospital discharge records with the incidence based upon expert review of 
patient medical records. The estimated based upon computerized hospital discharge data was very similar to that based upon chart review: incidence rate ratio 1.0 (95\% confidence interval (CI) 1.00 to 1.02 ) (table 1). Computerized hospital discharge data overestimated motor vehicle traffic injuries by about $10 \%$, with most of these errors resulting from using motor vehicle traffic codes for injuries that should have been coded to some other mechanism, such as off-road injuries. Computerized data tended to overestimate "other" and "unspecified" injuries: approximately $20 \%$ of injuries assigned to these general categories could have been coded to a specific mechanism.

Nearly $20 \%$ of hospitalizations due to late effects of injury were misclassified in computerized discharge records as acute injuries, leading to inflated estimates of acute injuries. Among cases that were correctly classified as late effects of injury, the expert reviewer found that $95 \%$ of the patients had been previously hospitalized for the injury. Data needed to answer the question "Is this the first hospitalization for this injury" was available for $95 \%$ of the cases.

Computerized hospital discharge records under-reported injuries of undetermined intent by $48 \%$. The incidence ratio comparing the computerized data with the expert review record was 0.52 (95\% CI 0.15 to 0.90$)$. These injuries were commonly misclassified as unintentional.

The overall amount of agreement between computerized hospital discharge data and records based upon expert review of actual medical charts was $87 \%$ for mechanism of injury and $95 \%$ for intent of injury. The amount of agreement was substantially lower $(66 \%)$ for the complete $\mathrm{E}$ code. The sampling design employed for this study allowed indepth analysis of coding for four categories of injury: falls, motor vehicle traffic injuries, poisonings, and firearm injuries. For each of these four injury mechanism groups, computerized hospital discharge records identified discharges for this mechanism, as defined by the expert review of medical records, with a sensitivity of $91 \%$ or better (table 2 ). Predictive value positive of the computerized data ranged from $88 \%$ for motor vehicle traffic injuries to $94 \%$ for poisonings. The most common type of error impacting the predictive value positive for all four subgroups was the misclassification of late effects of injury as acute injuries. The predictive value positive of motor vehicle codes was also impacted by misclassification of off-road injuries as motor vehicle traffic events. For poisonings, the predictive value positive of

Table 2 Estimates of the sensitivity (\%) and predictive value positive (\%;PVP) of selected mechanisms of injury: computerized hospital discharge data compared with expert review of medical records

\begin{tabular}{lll}
\hline Mechanism & $\begin{array}{l}\text { Sensitivity } \\
\text { (95\% CI) }\end{array}$ & $\begin{array}{l}\text { PVP } \\
\text { (95\% CI) }\end{array}$ \\
\hline Falls & $95.1(92.5$ to 96.8$)$ & $93.3(90.4$ to 95.3$)$ \\
Motor vehicle traffic & $96.6(91.4$ to 98.7$)$ & $87.6(80.8$ to 92.2$)$ \\
Poisoning & $98.9(92.6$ to 99.8$)$ & $94.2(90.1$ to 96.6$)$ \\
Firearms & $91.6(61.1$ to 98.7$)$ & $93.8(91.2$ to 95.6$)$ \\
\hline
\end{tabular}

Table 3 Estimates of agreement (\%) on coding of intent and the complete $E$ code for selected mechanisms of injury: computerized hospital discharge data compared with expert review of medical records

\begin{tabular}{lll}
\hline & Agreement & Kappa $^{*}$ \\
\hline All mechanisms of injuryt & 86.9 & 0.83 \\
Intent coding & 95.3 & 0.81 \\
Complete E code & 66.1 & 0.64 \\
Falls & & \\
$\quad$ Intent coding & 99.3 & 0.40 \\
$\quad$ Complete E code & 66.1 & 0.55 \\
Motor vehicle traffic & & \\
$\quad$ Intent coding & 98.4 & 0.00 \\
$\quad$ Complete E code & 63.3 & 0.60 \\
Poisoning & & \\
$\quad$ Intent coding & 86.6 & 0.72 \\
$\quad$ Complete E code & 72.2 & 0.67 \\
$\quad$ Firearms & & \\
$\quad$ Intent coding & 83.6 & 0.73 \\
$\quad$ Complete E code & 56.7 & 0.50 \\
\hline
\end{tabular}

*The kappa statistic measure of agreement is scaled to be 0 when the amount of agreement is what would be expected by chance and 1 when there is perfect agreement, adjusted for chance.

†This category includes all mechanisms of injury identified in table 1 .

coding was further reduced by the use of accidental or intentional poisoning codes to classify adverse effects of medications in therapeutic use.

The amount of agreement for intent coding ranged from $84 \%$ (0.81 kappa) for firearm injuries to $99 \%$ (0.40 kappa) for falls (table 3$)$. Disagreement on intent coding for firearm injuries reflected disagreement as to whether an incident was an accident, assault, or incident of undetermined intent. For poisonings the amount of agreement was $87 \%$ (0.72 kappa): the expert reviewer often classified a poisoning as unintentional when the computerized hospital discharge data classified the episode as suicide, despite the absence of evidence of either suicidal intent or depression in the medical record.

The complete E code contains details about an injury that are potentially useful for injury prevention and program planning. We found that the amount of agreement for coding of the complete E code ranged from 57\% (0.50 kappa) firearm injuries to $72 \%$ (0.67 kappa) for poisonings. Based on these estimates, it appeared that computerized hospital discharge data lacked the precision needed to identify the status of the injured persons in motor vehicle traffic injuries (driver, passenger, pedestrian, etc); the circumstances of falls (for example, falls from one level to another, falls on the same level due to slipping or tripping); the drugs involved in poisoning incidents; and the role of handguns compared with long guns in firearm injuries.

\section{Discussion}

We found that computerized hospital discharge data can be used with confidence to determine how many injuries are treated in a hospital setting in Washington State and the relative magnitude of various categories of injury. We also found that $\mathrm{E}$ codes on hospital discharge records are a reliable source of information on the mechanism and intent of injury, the two types of information most often used for injury 
related analyses and priority setting. In comparing the coding of records by intent, we found that agreement regarding intent was excellent $(98 \%)$ for injuries related to motor vehicle crashes, but the kappa statistic was zero, suggesting no agreement beyond chance. This arose because all of the computerized records for motor vehicle injuries were coded as unintentional; kappa will always be zero in this situation, regardless of the level of agreement. Similarly, agreement regarding the intent of fall related injuries was excellent $(99 \%)$, yet kappa was only 0.40 ; in this extreme situation, where virtually all the injuries were unintentional, the kappa statistic is not very helpful.

We found that hospital discharge coders tend to overuse non-specific E codes. However, consistent with the findings of Langlois and associates, ${ }^{12}$ we also found that deficiencies in chart documentation contributed to the use of non-specific codes. More complete documentation would enhance the quality and usefulness of injury data; specifically, more efforts need to be made to identify the status of the injured person in motor vehicle related incidents; establish the intent of injuries; and distinguish unintentional or suicidal poisonings from adverse effects of medications in therapeutic use.

The main limitation of the data was the lack of precision in the complete $\mathrm{E}$ code. This finding is consistent the study of Schwartz et al regarding the accuracy of $\mathrm{E}$ codes assigned to 108 emergency department records at a single hospital. ${ }^{13}$ Researchers who need injury data at the complete E code level should consider sources other than hospital discharge data. At a minimum, researchers must exercise caution in interpreting and using detail codes. It cannot be assumed that ICD-9-CM codes designated for very specific events and circumstances are used consistently or appropriately.

A recurring issue found in this study was the vague nature of the "late effects" category, and the impact that this has on injury estimates. The language in ICD-9-CM does not clarify which injuries are to be regarded as late effects and which are not. As a result, there was considerable interhospital variation in the use of these codes. Some hospitals coded any admission to a rehabilitation unit as a "late effects" admission, while others required some period of time to pass (anywhere from three to 12 months) before an injury admission was considered to be a late effect. A more useful distinction might be one that clearly identifies whether an admission is the first one related to a specific injury, as suggested by Smith and associates. ${ }^{14}$ This would allow a clearer identification of acute injuries, and therefore more accurate estimation of injury incidence from hospital discharge data.

The complexity of injury coding guidelines, combined with the fact that these rules are subject to change, suggests that medical record coders need periodic training on injury coding to stay abreast of current requirements and maintain a high level of coding accuracy. There are indications that training needs are not being met. During the course of our study the

\section{Key points}

- Computerized hospital discharge data can be used to estimate the number of injuries treated in a hospital setting.

- External cause of injury codes on hospital discharge records are a reliable source of information on the mechanism and intent of injury.

- The main limitation of hospital computerized data is lack of precision in the detail code-that part of the E code after the decimal place which identifies specific circumstances of an injury.

- "Late effects" of injury are frequently coded as acute injuries.

rules for coding intent of injury underwent a major change-before October, 1996 the instructions for coding intent stipulated that "if the intent (accident, suicide, assault) of an injury or poisoning is not specified or unknown, code the intent as accidental". In October, the rules changed to require that such injuries be coded as intent undetermined. Subsequent discussions with medical record personnel revealed that most coders were unaware of these changes.

The findings of this study have implications for the quality of future injury data. In 1999, states implemented the ICD-10 classification scheme for mortality coding. In a few years, hospitals will adopt the ICD-10-CM for morbidity coding. The ICD-10 classification scheme for injuries will provide more injury codes, allowing injuries to be described in much greater detail than before. However, the existence of codes does not assure that these codes will be used consistently and accurately. To realize the promise of the ICD-10 injury classification scheme, work needs to be done to ensure that the creators of the classification scheme provide clear guidelines on their use; that health care professionals are trained and able to provide the needed documentation in medical records; and that hospital coders are trained to understand and apply the new injury coding requirements.

The authors gratefully acknowledge support for this study from Ms I Silver, Program Manager, Washington State Injury Prevention Program, and Mr H Brown, Ms V Hohner, and Ms D Johnson from the Office of Hospital and Patient Data. The authors would also like to thank Mr D Keck and Mr J Judkins for assistance in preparing computerized data sets, and Ms C Hill for expert review of medical charts. This work was supported in part by a grant from the Centers for Disease Control and Prevention, Atlanta, Georgia (R49/CCR002570).

1 Buyer B, Berenholz G, Gallagher SS. Injury surveillance using hospital discharge abstracts coded by external cause of injury (E code). F Trauma 1990;30:470-3.

2 Sniezek JE, Finklea JF, Graitcer PL. Injury coding and hospital discharge data. $\mathscr{f} A M A$ 1989;262:2270-2.

3 US Department of Health and Human Services. International classification of diseases. 9th Revision, clinical modifications (ICD-9-CM). 6th Ed. Washington, DC: US DHHS, Public Health Service, Health Care Financing Administration, DHHS Publication No (PHS) 96-1260, 1997.

4 American Public Health Association. How states are collecting and using cause of injury data. San Francisco, CA: APHA, 1998.

5 Marganitt B, MacKenzie EJ, Smith GS, et al. Coding external causes of injury (E-codes) in Maryland hospital discharges 1979-88: a statewide study to explore the uncoded population. Am F Public Health 1990;10:1463-6.

6 Levy PS, Lemeshow S. Sampling of populations: methods and applications. 3rd Ed. New York: John Wiley, 1999: 342-57, 
7 US Department of Health and Human Services. Official ICD-9-CM guidelines for coding and reporting. Hyattsville, MD: National Center for Health Statistics, October 1995 8 US Department of Health and Human Services. Official ICD-9-CM guidelines for coding and reporting. Hyattsville, MD: National Center for Health Statistics, October, 1996.

9 McLoughlin E, Annest JL, Fingerhut LA, et al. Recommended framework for presenting injury mortality data. MMWR Recommendations and Reports 1997;46(No RR14): $1-30$.

10 Fleiss JL. Statistical methods for rates and proportions. 2nd Ed. New York: John Wiley, 1981: 212-25.
11 StataCorp. Stata statistical software: release 6.0. College Station, TX: Stata Corporation, 1999

12 Langlois JA, Buechner JS, O'Connor EA, et al. Improving the E-coding of hospitalizations for injury: do hospital records contain adequate documentation? Am f Public Health 1995;85:1261-5.

13 Schwartz RJ, Nightingale BS, Boisoneau D, et al. Accuracy of e-codes assigned to emergency department records. Acad Emerg Med 1995;2:615-20.

14 Smith GS, Langlois JA, Buechner JS. Methodological issues in using hospital discharge data to determine the incidence of hospitalized injuries. Am f Epidemiol 1991;134:1146-58.

Unattended vehicles: $\mathbf{5 4}$ deaths last year attributed to parents making mistakes

Child safety advocates say people are in denial if they think only an unemployed security guard could make the fatal mistake of leaving his baby strapped in a hot car for hours, as happened in San Jose last week. Last year, at least 54 children left alone in cars were killed by heatstroke or accidentally pinned by automatic windows. Others died after setting the car rolling or after starting a fire with the cigarette lighter, said Janette Fennell, founder of Kids'N Cars. The San Francisco non-profit group advocates public education and legislation to prevent children from needlessly dying in vehicles.

"Last year, eight dads on their way to work left their kids in the car when they forgot to drop them at day care. All the kids died", Fennell said. "None of these were deadbeat dads. There was a NASA engineer, a high school teacher, a webmaster, a lawyer. These are people who truly forgot the baby was in the back seat".

Last month in Iowa, a mother preoccupied with the pressures of her hospital executive job remembered to drop off her 3 year old son at day care. But Kari Engholm forgot her 7 month old daughter until she found her lifeless body in the back of the family minivan at the end of a hot day. She's been charged with involuntary manslaughter. Her husband, who normally dropped the daughter off, said the change in routine and his wife's hectic schedule contributed to the tragedy.

Safety advocates say deaths are a symptom of a society where working parents are too tired, distracted, or thrown off by a change in routine. The forgetfulness may be compounded by fatal airbag accidents in the mid-1990s that spurred parents to place small children in the back seat, where sleeping infants in rear-facing car seats more easily go unnoticed.

"Everyone wants it to be a freak accident. It's not a freak accident when we've got 54 dead children nationally this year", Fennell said. In the past five years, at least 120 children have died in hot vehicles, according to research by the National SAFE KIDS Campaign and General Motors.

(San Francisco Chronicle, July 2001. Contributed by Deborah Stewart) 